\title{
On the issues of digital competence in educational contexts - a review of literature
}

\author{
Fanny Pettersson ${ }^{1}$ (D)
}

Received: 9 June 2017 / Accepted: 3 September 2017 / Published online: 14 September 2017

(C) The Author(s) 2017. This article is an open access publication

\begin{abstract}
In this review focus is on how digital competence in educational contexts has been addressed in international research over the last 10 years in terms of policy, organizational infrastructures, strategic leadership as well as teachers and their teaching practices. The analysis shows that although research on digital competence in educational contexts has increased, knowledge on digital competence related to organizational infrastructures and strategic leadership are sparse. The analysis indicated that most research focuses on the specific competence needed by teachers and therefore tends to neglect the influence of broader contextual conditions in the wider school setting. Based on the review, three suggestions for further research can be provided. Firstly, to address research on organizational infrastructures and digital competent leadership. Secondly, to elaborate on theoretical frameworks that can close the gap between research on policy, organizational infrastructures, strategic leadership as well as teachers and their teaching practices. A third suggestion is for researchers to become involved in the development of new approaches that can enhance digital competence in educational contexts. It can be concluded that digital competence might not benefit from being regarded as an isolated phenomena on the level of single actors. Rather, it can be regarded as an organizational task, influenced and driven by several contextual factors embedded within and across a wider school organization.
\end{abstract}

Keywords Digital competence · Digital literacy · Policy · Teacher · School leader · Organization

\section{Introduction}

The last decade has seen an increased interest in the concept of digital competence. From a European perspective, digital competence has been used in different areas to

Fanny Pettersson

fanny.pettersson@umu.se

1 Department of Education, Umeå University, Umeå, Sweden 
describe competences needed in a digitalized knowledge society (Hatlevik and Christophersen 2013). One of those areas is policy-related papers in which digital competence has occurred as a shared object of change and development (Ala-Mutka et al. 2008; Balanskat and Gertsch 2010; Hatlevik and Christophersen 2013). Another area is research where digital competence has been examined and discussed (see Ilomäki et al. 2016; Krumsvik 2012).

Generally speaking, digital competence often refers to the skills and literacies needed for the average citizen to be able to learn and navigate in digitalized knowledge society (Ilomäki et al. 2016). Ferrari (2012) defined digital competence as:

'the set of knowledge, skills, attitudes, abilities, strategies and awareness that are required when using ICT [information and communication technologies] and digital media to perform tasks; solve problems; communicate; manage information; collaborate; create and share content; and build knowledge effectively, efficiently, appropriately, critically, creatively, autonomously, flexibly, ethically, reflectively for work, leisure, participation, learning and socialising' (p. 30).

This definition illustrates a comprehensive inclusion of numerous skills and abilities, carrying a general meaning and scope to be discussed on a macro level of the average citizen acting in various areas of society (Krumsvik 2012). This paper, though, shifts focus towards the pedagogical aspects of digital competence by zooming in on educational contexts. What can be noted is that although much research on digital competence in educational contexts has emerged, it still seems to be a confusion and inconsistency between digital competence among average citizens and the pedagogical aspects of digital competence needed for the specific actors working in school and education. One assumption in research literature of why is it that teachers and school leaders' digital competence for example denotes a more complex set of skills and competences compared to digital competences needed in other areas of society (From 2017; Instefjord and Munthe 2016; Krumsvik 2012). Moreover, teachers and school leaders' digital competence appear in complex organizational systems and act within rich educational traditions which enhances the complexity when the competence is enacted in educational contexts (Krumsvik 2008; Lund et al. 2014).

\subsection{Towards pedagogical aspects of digital competence}

Modern digitalization has meant an increasingly complex school environment (Hatlevik and Christophersen 2013). As digital technologies ${ }^{1}$ are becoming a central part of the everyday work, teachers are forced to rethink and transform previous educational traditions by means of technology. These challenges have created considerable demands for schools with regards to developing strategies to support the digital competences needed for providing high quality teaching and learning. In recent years, a number of attempts have been made to elaborate on the digital competence needed for actors working in school and education (From 2017; Howell 2012; Kivunja 2013; Krumsvik 2008, 2009; Krumsvik et al. 2016). For instance, Howell (2012) described

\footnotetext{
${ }^{1}$ In this paper, digital technologies comprise several terms like ICT, computers, laptops, learning management system (LMS) and digital media such as blogs, social media, and wikis (see Olofsson et al. 2015).
} 
digital pedagogy in terms of 'how to teach using digital technologies'. Kivunja (2013) described digital pedagogy in terms of 'the art of teaching, computer driven digital technologies, which enrich learning, teaching, assessment and the whole curriculum' (p. 131). In another study, From (2017) put focus on pedagogical aspects as a specific characteristic of the broader term of digital competence. Similarly, Krumsvik (2008) suggested an inclusion of pedagogical aspects into the concept of digital competence and Krumsvik (2011) definition reads, 'the teacher/TEs' [teacher educators'] proficiency in using ICT in a professional context with good pedagogic-didactic judgement and his or her awareness of its implications for learning strategies and the digital Bildung of pupils and students' (p. 45).

Throughout recent years, attempts have also been made in discussing pedagogical aspects of digital competence from a contextual perspective (From 2017; Wastiau et al. 2013; Vanderlinde and van Braak 2010). From (2017) argued, for example, that the pedagogical aspects of digital competence should not only be regarded as a separate set of skills and competences embedded at the level of teachers but also be embedded within and across the wider school organization. In the same line of reasoning, Vanderlinde and van Braak (2010) put forth the importance of supportive organizational infrastructures, formation of policy-related documents and a strategic leadership that can support teachers in transforming policies into realistic goals while teachers can put these goals into action in the everyday teaching practice. Also Wastiau et al. (2013) argued for a comprehensive organization of policies, leadership and supportive organizational infrastructures when trying to achieve technology integration and development of the digital competences needed.

These examples above indicate the complexity of digital competence when applied in educational contexts. Moreover, what it might take to develop digital competence and what such competence might look like in today's digitalized schools. The aim of this paper is to further elaborate on these issues by reviewing how pedagogical aspects of digital competence has been addressed in international research between the years 2007 and 2017 in terms of policy, organizational infrastructures, strategic leadership as well as teachers and their teaching practices. In doing so, this review will provide a discussion on critical aspects related to each of these four themes. It concludes with suggestions for future research and limitations of the study.

\section{Methodological considerations}

A qualitative review of literature was conducted to examine how pedagogical aspects of digital competence has been addressed in international research between the years 2007 and 2017 in terms of policy, organizational infrastructures, strategic leadership as well as teachers and their teaching practices. The logic behind the search of literature was to find research on digital competence in different educational contexts. The search was focused on locating results from different perspectives in the educational research field. This approach can be understood as a paradigmatically inclusive review where the logic behind the search allows for various theoretical standpoints, methodological considerations and empirical as well as non-empirical studies to be included in the review (Suri and Clarke 2009; Rantatalo 2012). 


\subsection{Search procedure}

The search was conducted using the search engine EBSCOhost, including the databases Education Resources Information Center (ERIC) and Academic Search Elite. As a way to assure the scientific quality, it was decided to only include international peerreviewed research published in scientific journals and books. The following three limitations, decided on beforehand, were applied: 1) published between 2007 and 2017, 2) research written in English and 3) with full-text availability. The search terms used derived from both the author's previous reading of literature in this research field and the use of terms frequently used in research specifically related to pedagogical aspects of digital competence. In this way, the search procedure was understood as including a more general as well as specific focus.

In the first search attempt, the following terms: 'digital competence' or 'pedagogical digital competence' or 'digital skill' or 'ICT-competence' or 'digital pedagogy' or 'digital literacy' returned articles and book chapters in a wide range of areas (for example school, higher education, organizations, ministries, world bank). In an attempt to further limit the search to only include the field of education, the terms of 'school', 'education', 'classroom', 'policy', 'leadership', 'school leaders' and 'teachers' were added to the first set of search terms. Here EBSCOhost allowed for combinations of terms (by using for example +/and/or) as well as the exclusion of the terms 'pupils' and 'children' (due to the focus on pedagogical aspects of digital competence among actors working in educational contexts). In total, 368 articles and book chapters were given as results.

\subsection{Inclusion of articles}

After the search was completed, the identified articles and book chapters were saved and organized using Mendeley software $\subset$. To guarantee a trustworthy, robust and repeatable review with high validity and reliability, the inclusion of research used a systematic approach with six pre-determent criteria's (similar to Suri and Clarke 2009; Stödberg 2012). The following six criteria were established:

- Research should concern educational contexts (e.g., teachers, leadership, organization, policy).

- Research should concern pedagogical aspects of digital competence needed for actors working in educational contexts.

- Research should concern competence or literacy with connection to digital technology.

- Research should include pedagogical aspects of digital competence.

- Research should not focus on professional development or learning with digital technologies in general.

- Research should not focus on students, pupils or children's digital competence.

In this step, titles and abstracts and, in some cases, the conclusion of articles and book chapters were narrowed to scrutinize the relevance of its content. If during this reading it appeared as if an article or book chapter did not meet all the criteria for the review, it was consequently excluded. For example, the terms 'school', 'classroom' and 
'education' produced a large number of literature focusing on students' and pupils' digital competence (and not the pedagogical aspects of digital competence needed for actors working in school and education), which did not meet the criteria. Other examples were research focusing on learning and professional development with digital technologies in general and not including a specific focus on development of digital competence. Out of the 368 publications included for an initial review, 34 were chosen for inclusion in the next stage. It shall here be noted that an additional seven peerreviewed articles were included by means of 'citation snowballing', i.e. by scanning and selecting references in the previously included articles and book chapters (similar to Boote and Beile 2005). Altogether, 41 pieces of literature - articles $(N=38)$ and book chapters $(N=3)$-were identified fitting the criteria's and for inclusion in the final stage of the review.

The 41 pieces of literature retrieved were then screened to assure their eligibility. Thereafter, as a rule for organizing the articles and book chapters, the documents were read through and sorted according to four themes decided beforehand. That is: (1) policy $(N=12)$, (2) organizational infrastructures $(N=6)$ (3) strategic leadership $(N=8)$ and (4) teacher and their teaching practices $(N=20)$ (see Table 1 below) (compare, Bray and Thomas 1995). Some texts $(N=7)$ contained content that addressed more than one theme.

Thereafter, to organize and analyse the text within each theme, the literature was reread and analysed by means of a thematic content analysis. This was done by following

Table 1 Themes, including articles and book chapters

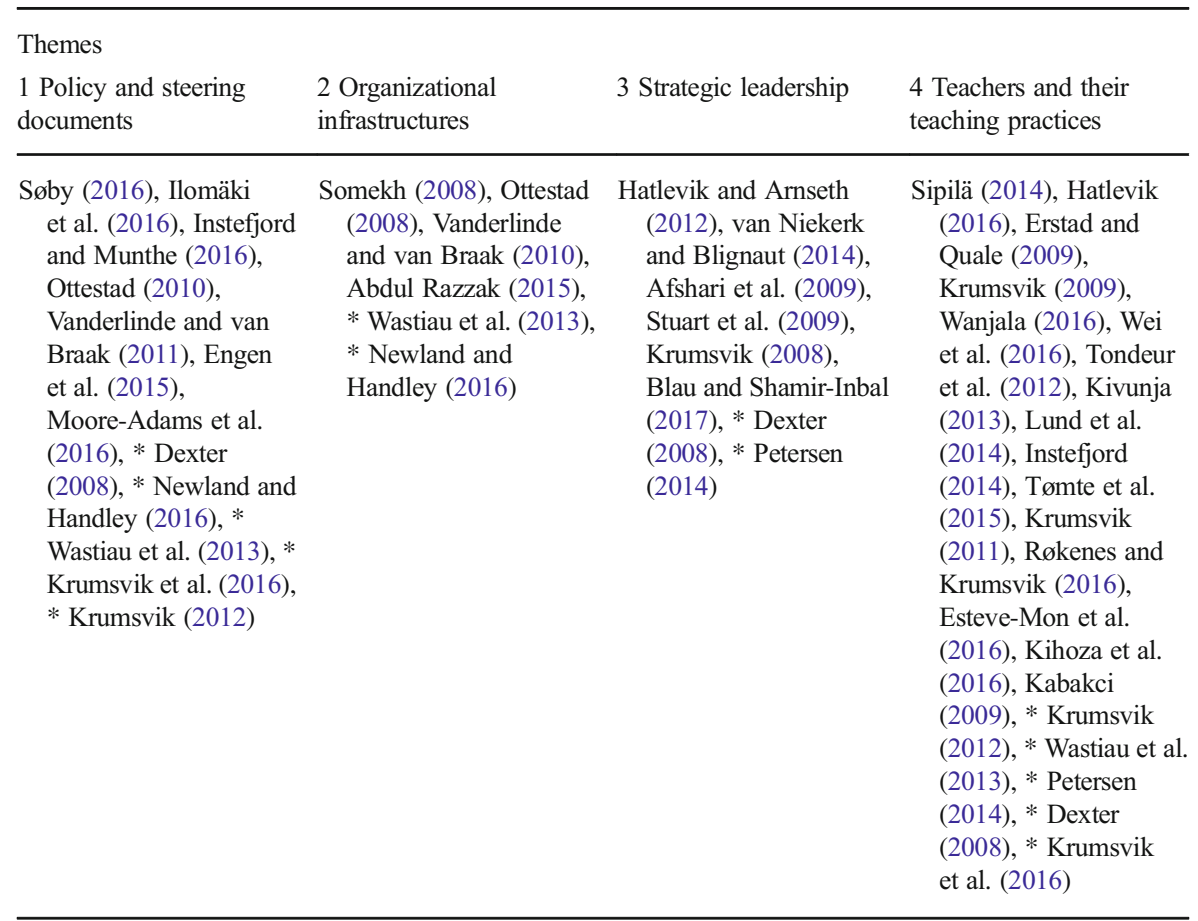

*Included in more than one theme $(N=6)$ 
a broad procedure of coding and categorizing inspired by Hjerm and Lindgren (2010). After coding text-materials by giving them names that described their content, codes that appeared to be related were assembled. This process resulted in a reduction of codes into a total of 12 inductive sub-themes. The four themes including sub-themes are presented in the section below.

\section{Results}

In this section, findings from the review are presented. The section is organized in accordance to the four themes: (1) policy and steering documents, (2) organizational infrastructures, (3) strategic leadership, and (4) teachers and their teaching practices.

\subsection{Policy and steering documents}

The first theme concerns pedagogical aspects of digital competence and how it occurs in research on policy. What appears in the analysis is how digital competence has been used to create a public debate between stakeholders in educational contexts (Ilomäki et al. 2016). As argued by Søby (2016), digital competence has become a shared object between research, policymakers and practitioners. It can also be noted that policy has made digital competence an objective in itself by promoting teachers' professional development (TPD) in different educational settings (e.g., Krumsvik et al. 2016).

According to the analysis, the first inductive sub-theme from the analysis shows that the possibility to promote the development of digital competence in an educational context implies that it needs to be clearly formulated in policy (Instefjord and Munthe 2016; Krumsvik 2012; Wastiau et al. 2013), and when so, that it is used as an argument to set the agenda for school innovation and educational changes (Søby 2016). For example, Krumsvik (2012) as well as Instefjord and Munthe (2016) pointed at the emergent need for knowledge on how digital competence to be integrated into institution-wide policies so that teachers can meet the requirements of today's digitalized schools. In the same line of reasoning, Wastiau et al. (2013) suggested a solid formalization in policy of TDP activities in both schools and education.

The second sub-theme acknowledges the importance of digital competence being firmly anchored in policies on multiple levels of the educational system to enable for educational change (Dexter 2008; Newland and Handley 2016; Wastiau et al. 2013). For example, Dexter (2008) placed focus on the significance of polices to be formulated on regional or municipal level. According to Dexter, these policies can then be transformed into concrete goals and activities at the school level. Wastiau et al. (2013) in their work argued for policymakers to make it possible to develop digital competence at various levels of the educational system, from the national to the local school level. Wastiau et al. further promoted policies and actions at the EU level to clearly find the conditions and patterns for TPD as well as how to mainstream these initiatives in different educational contexts. A related strand in the analysis focuses on how to make use of broader organizational policies for promoting the development of actors' digital competence. For example, how policies related to digital competence can be developed and initiated as a part of already established school- and education-wide strategies of technology implementation or educational change. In their study elaborating on policy 
development related to larger educational strategies, Newland and Handley (2016) stated that the development and implementation of policies on digital competence went straightforward since 'they clearly aligned with the University's strategic commitment to digital transformation, drew on teams from across the University and (therefore) had the backing of senior management through the committee process' (p. 9).

A third sub-theme relates to what extent digital competence is formulated in policy (Engen et al. 2015; Moore-Adams et al. 2016; Ottestad 2010; Vanderlinde and van Braak 2011; Wastiau et al. 2013). Acknowledging that digital competence (both on and off) is integrated in policy-related documents, there seems to be a coherent call for additional policies and actions. In the review, several concluding remarks point at the emerging need of policy actions related to digital competence at all levels of the educational system (Wastiau et al. 2013). As shown by Ottestad (2010), while pupils' digital competence seems to be clearly formulated in policies, TPD to meet the need of those learners is not realized uniformly and differences among interpretations, activities and approaches to enhance teachers' digital competence occurs. Similar conclusions were made in the literature on teacher education, in which researchers point at digital competence as not being anchored in the steering documents (e.g., Engen et al. 2015). In their research review on teacher preparations for teaching online, Moore-Adams et al. (2016) noticed that despite the need for high quality teachers, teachers are often placed in digitalized educational settings without formal training in the pedagogical use of ICT. Moore-Adams et al. (2016) argued that researchers and policymakers should in the future be required to not only initiate TPD but also put focus on the pedagogical dimensions of technology use in relation to a specific subject or educational setting. Vanderlinde and van Braak (2011) phrased it in terms of "primary function of most educational policies is to provide schools with funding and resources for equipment, network infrastructure, and to a lesser extent, the professional development of teachers' (p. 124).

\subsection{Organizational infrastructures}

The second theme is concerned with how pedagogical aspects of digital competence has been addressed in research on organizational infrastructures. The first inductive sub-theme from the analysis relates to school organizations and their ability to provide supportive infrastructures (Newland and Handley 2016; Somekh 2008; Vanderlinde and van Braak 2010). Somekh (2008) argued that such infrastructures are crucial for developing the pedagogical use of digital technologies in school. On that matter, Somekh put forth that 'organisational structures of schooling often make it impossible for ICT tools to be explored and appropriated pedagogically' and further that educational systems 'can be understood as outdated infrastructures resisting inevitable change' (p. 450). Also other researchers come to similar conclusions when promoting structural and cultural change to provide sustainable and system-wide support for development of digital competences (Newland and Handley 2016; Vanderlinde and van Braak 2010).

The second sub-theme is comprised of digital competence as a specific characteristic of a school organization (Ottestad 2008; Vanderlinde and van Braak 2010). Two examples are comprised of the capabilities or capacities in a school and what appears to resemble schools and organizations' digital competence (Ottestad 2008; Vanderlinde 
and van Braak 2010). Ottestad (2008) found four indicators of a 'digitally competent school'. These were organizational competences or processes that schools need to implement to become digitally competent. Namely, to develop the staff's digital competence, building a culture that facilitates sharing of knowledge, to produce plans and strategies with a pedagogical focus and to make strategic investments of resources and support measures. Another example is Vanderlinde and van Braak's (2010) emphasis on the e-capacity of a school. The authors describe e-capacity as the ability or 'collective competence of a school to implement ICT in a way that is a lever for instructional change' (p. 542). In their study, a number of key concerns were identified, operationalized and brought together in an e-capacity model including the aspects of school leadership, goals and visions, policy planning, decision making, technology infrastructures, technology coordination and support, collegiality, professional development, teachers' digital competence and, finally, the pedagogical use of digital technologies in the educational context. Subsequently, the model denotes what a school organization can accomplish by realizing, creating and sharing different resources as well as what school organizations are able, willing and forced to go through to achieve e-capacity and become organizationally competent. However, conclusions can be drawn from Ottestad (2008) and Vanderlinde and van Braak (2010), additional research related to digitally competent school organizations is needed.

The third sub-theme is comprised of the supportive school culture (Abdul Razzak 2015; Wastiau et al. 2013). Abdul Razzak (2015) showed that schools must develop a tolerant school culture that encourages teachers and school leaders' exploration of new teaching designs through professional development in digital competence. In a similar study Wastiau et al. (2013) implied that schools, defined as digitally supportive schools, often succeed in combining ICT policies with a culture of informal and formal support measures such as TPD.

\subsection{Strategic leadership}

Theme 3 concerns pedagogical aspects of digital competence as it relates to research on strategic leadership. In this theme there seems to be an agreement that strategic and digital competent leadership needs to be further addressed as a field of research. In the first inductive sub-theme, relates to how school leaders are becoming increasingly important to translate and concretize policies on digital competence and ICT into realistic goals and concrete support actions at local schools (Dexter 2008; Hatlevik and Arnseth 2012; Petersen 2014). Hatlevik and Arnseth (2012) mean that school leaders' priorities and decisions are essential for teachers' use of digital technologies in the classroom. Dexter (2008) here pointed out three important functions of educational ICT leadership in school. In her study, the conclusions pointed at school leaders' capacity to formulate goals and visions for 'setting the direction', providing rich and supportive learning environments for 'developing staff' and taking the necessary steps to 'making the organization work' by creating supportive institutional infrastructures. Such a comprehensive leadership, Dexter argued, must rest on the collaboration between professionals in the educational context, including transforming policies into realistic goals and formulating paths for professional development. In the same line of reasoning, Petersen (2014), in a study on digital competence and ICT leadership, stressed the importance of system thinking and team-based leadership structures 
composed of actors with different competencies when building for development of digital competence and educational change.

The second sub-theme is related to school leaders' digital competence being a main barrier for transforming ICT-policies into system-wide professional development and educational change (Afshari et al. 2009; Dexter 2008; Petersen 2014; Stuart et al. 2009). For example, Stuart et al. (2009) described how school leaders are exposed to increasing demands when digital technologies are integrated into the everyday work of school. These researchers stated that in order to take action in digitalized schools, school leaders must realize the possibilities and constraints in educational technologies and to become pedagogically and technologically competent in their role as ICT leaders. According to the analysis, a possible solution put forth by Afshari et al. (2009) as well as Stuart et al. (2009) is school leaders participating in continuing professional development (CPD). In the same line of reasoning, Dexter (2008) and Petersen (2014) found that CPD should include both development of digital competence in using digital technologies and digital competence in how school and institutional infrastructures should to be organized to facilitate the everyday work in digitalized schools.

According to the analysis, the third sub-theme concerns research on the importance of school leaders both changing their attitudes towards digital technologies and that they become more involved in the everyday integration of digital technologies and professional development of digital competence (Krumsvik 2008; van Niekerk and Blignaut 2014). For example, van Niekerk and Blignaut (2014) argued that school leaders 'cannot remain bystanders that assume their teachers are skilled in ICT' ( $p$. 249) but rather formulate and implement goals and strategies that support both the staff's and their own professional development. Other researchers put forth that school leaders must recognize specific needs in school settings and to make possible for their staff to participate in professional development activities in their everyday practice (Krumsvik 2008).

\subsection{Teachers and their teaching practices}

The fourth and final theme concerns the pedagogical aspects of digital competence in research on teachers and their teaching practices. From the analysis, it can be concluded that there seems to be an agreement that teachers' digital competence is important for uptake and use of digital technologies in teaching and learning practices. The first inductive sub-theme from the analysis concerns the impact of teachers' digital competence when it comes to ICT integration and pedagogical use of digital technologies (Blau and Shamir-Inbal 2017; Hatlevik 2016; Sipilä 2014; Wastiau et al. 2013). Blau and Shamir-Inbal (2017) examined (from a school leader perspective) teachers' digital competences as one important component for ICT integration and pedagogical changes. In their study, they found that ICT integration and digital competence evolves over time and that digital competences must become an integral part of teachers' core teaching competences and not as something that is 'an add-on'. Hatlevik (2016) as well as From (2017) put forth that digital competence is an aspect that can explain variations in teachers' pedagogical use of digital technologies and that high levels of digital competence can contribute to a more critical and frequent use of digital technologies. In their study, Wastiau et al. (2013) showed that teachers' confidence in their own 
digital competence influence students' use of technologies during lessons. Moreover, students taught by teachers with a high digital competence but with limited access to digital technologies in the classroom use digital technologies to a greater extent than those taught by teachers with a low digital competence but with free access to technologies. This indicates that (research on) teachers' digital competence can be understood as more important than a rich access to digital technologies in schools. A similar result can be found in Sipilä's (2014) work, which showed that students need competent and confident teachers to make use of rich digital learning environments.

According to the analysis, the second sub-theme is comprised of the importance of different forms of TPD for the enhanced uptake and pedagogical use of digital technologies in educational contexts (Dexter 2008; Erstad and Quale 2009; Kabakci 2009; Krumsvik et al. 2016; Wanjala 2016; Wastiau et al. 2013; Wei et al. 2016). Erstad and Quale (2009) argued that teachers are 'faced with a frustrating dilemma: they are required by statute to use ICT extensively in their practice, but no one tells them how they should do this' (p. 565). In their study, Wei et al. (2016) investigated the uptake and use of a school management system in a secondary school in Malaysia. They concluded that ongoing TPD to enhance teachers' digital competence facilitated effective uptake and use of digital technologies in teaching and learning practices. This conclusion is in line with Wanjala (2016), who found that TPD to enhance teachers' digital competence is crucial for the extent to which teachers design teaching and learning activities through technologies. Wastiau et al. (2013) further claimed that informal learning settings, professional online learning communities and other types of TPD initiatives that are 'closely integrated into teachers' daily practice' can be of importance for teachers' continuing development of digital competence (p. 23). Similarly, Dexter (2008) in line with Wastiau et al. (2013) pointed out the need for school networking on local or regional basis, where expertise in and practices on digital competence can be shared within and across school settings.

The third sub-theme is related to digital competence in teacher education (EsteveMon et al. 2016; Hatlevik 2016; Instefjord 2014; Kihoza et al. 2016; Kivunja 2013; Krumsvik 2009, 2011, 2012; Lund et al. 2014; Tondeur et al. 2012; Tømte et al. 2015; Røkenes and Krumsvik 2016). The analysis shows that several research studies have addressed the importance of integrating approaches to digital competence into teacher education (Hatlevik 2016; Instefjord 2014; Kivunja 2013; Krumsvik 2011, 2012; Lund et al. 2014; Tømte et al. 2015). In their case study, Røkenes and Krumsvik (2016) followed four teacher-students' development of digital competence in Norwegian teacher education. In the study, they found a number of approaches to support students' by learning how to teach with technologies. The authors concluded that there is a need for systematic thinking about digital competence and technology integration into teacher education. In addition, teacher-educators must reflect on their own use of technologies in their teaching practices. With a similar focus, Tømte et al. (2015) explored to what extent teacher-educators actually encourage teacher-students to develop their digital competence by acting as role models in courses. Despite good avenues for presenting explicit examples and to stimulate student teachers' to elaborate their digital competences, the study revealed that few teachers used the opportunity. Krumsvik (2011), Tømte et al. (2015) and Tondeur et al. (2012) further argued that approaches, models and activities to enhance teachers and teacher students' digital competence often appear to be poorly integrated into teacher education and that further 
research is needed. In meeting these challenges, Kihoza et al. (2016) and Krumsvik (2009, 2012) suggested researchers' and practitioners' further theorization and operationalization of digital competence in teacher education curriculum. With similar focus, Esteve-Mon et al. (2016) developed a 3D model for evaluating teacher-students' digital competence. The model, which is based on educational design research further aims to support teacher-students' development of digital competences in their future teaching practices.

\section{Discussion and concluding remarks}

The aim of this review has been to examine how the pedagogical aspects of digital competence have been addressed in international research between the years 2007 and 2017 in regards to policy, organizational infrastructures, strategic leadership as well as teachers and their teaching practices. In this section, a discussion on each of the four themes will be made. Thereafter, conclusions and suggestions for future research and practice are presented. Finally, some limitations with the study is acknowledged.

According to the first theme related to policy, it can be noted how digital competence has become a shared object between stakeholders in educational contexts (Ilomäki et al. 2016; Søby 2016). For example, digital competence has been used to create a debate between research, policymakers and practitioners. Despite this, it seems as if no obvious consensus or shared knowledge has been developed on what digital competence in educational contexts 'is' and what the competence entails during the last 10 years of research investigated in this review. Rather, the meaning and scope of digital competence and its related concepts (e.g., digital pedagogy, ICT competence, digital literacy and pedagogical digital competence) seem seldom to be well-defined and are often used as synonyms when describing the competences needed for actors working in educational contexts. Accordingly, this seems to have resulted in a mix of concepts that potentially may carry the same meaning and scope. Another critical issue related to this theme concerns policies to be formulated on multiple levels of the educational system. In this theme, there seems to be an endeavour of holding entire school organizations responsible for development of digital competence. However, although policymakers seem to push their ideas on multiple educational levels, policies seem often to become a dilemma to be handled by teachers. A critical question for researchers, policymakers and school leaders appears to be how to steer the responsibility to an organizational level. Moreover, how to close the gap between policy level and the level of teachers when developing digital competence in the wider school organization.

The second theme related to organizational infrastructures, shows that while policies on digital competence may be useful on a general level, goals and visions preferable need to come down to supportive institutional infrastructures and concrete support measures (similar to Dexter 2008; Petersen 2014; Wastiau et al. 2013). An interesting aspect for future research related to this theme is how digital competence does not need to be excluded to single actors but can rather be seen as a school-level characteristic (meaning schools being digitally competent). To facilitate technology integration and educational change, schools can become digitally competent in their ways of structure and organize and mobilize resources and institutional infrastructures. This can be seen 
in research as a possibility for an entire school organization to take responsibility for educational change. On the other hand, a dilemma for these schools seems here to be lack of knowledge in how to combine policy with supportive institutional infrastructures, effective leadership and development of concrete support measures. Therefore, one example of a central issue would be for researchers to inform and discuss with school leaders about how policies related to digital competence can be cemented in educational contexts.

The third theme, shows the importance of a strategic leadership as a means to transform policies into realistic goals and supportive infrastructures. This review points towards school leaders to take lead in processes of technology integration and educational change. However, such demands seems to be rather challenging due to the inexperience and lack of readiness among school leaders in planning and directing work in digitalized schools. According to such demands, a critical question might be if the work and development of 'a digital competent leadership' should be excluded to single actors. Considering the work of school leaders being embedded in a complex educational context, strategic digital competent leadership might rather be thought of as a school-level assignment including various professions, actors and competences. The professional development of individual leaders might therefore not be enough for leading the work in digitalized schools. Rather, the strategic leadership would benefit from being developed and denoted in future research as an organizational developmental task led by various professions (e.g., school leaders, educational consultants, ICT facilitators and project leaders) as a part of a digitally competent school organization.

Although the analysis indicates that aspects of policies, organizational infrastructures and strategic leadership are important for developing digital competence, the main focus in much of the research appears to be on the fourth theme: teachers and teaching practices ( 21 articles and book chapters: 12 on policy, 6 on organization and 8 on strategic leadership). In this theme, several researchers focused on teachers' and their responsibility to plan, design and carry out teaching and learning activities (Sipilä 2014). On the one hand, there seems to be an underlying, or even normative, assumption that teachers are responsible for developing their own digital competence to meet the needs of students in digitalized schools. On the other hand, there seems also to be a critical voice pointing at a misdirected blame on the role of teachers. These voices call for future research on, and an enhanced responsibility to be taken by other levels in the educational system, for example, school leaders, school organizations and policymakers.

\subsection{Digital competence in the wider school organization}

When taking the analysis of the four themes together, the picture that emerges is of digital competence preferably not being regarded as a separate set of competences embedded among teachers but instead being viewed within a broader educational context (similar to Petersen 2014). What appears in the analysis is how the development of the digital competence required for today's digitalized schools depends on several contextual and institutional factors. The review shows how organizational structures of schooling can make it possible or not for staff to develop the competences needed. Moreover, schools, including strategic leadership, need to become digitally 
competent in their ways of structure and organize resources and institutional infrastructures to facilitate their staff to do the same (similar to Ottestad 2008; Vanderlinde and van Braak 2010).

As it seems, digital competence does not benefit from being regarded as an isolated phenomena on the level of single actors but should rather be seen as embedded within and across the wider school organization (similar to Hauge and Norenes 2012; Petersen 2014). Despite this, knowledge on digital competence at an organizational and leadership level seem to be sparse. The analysis indicates that most research is focused on the specific competence needed by teachers and therefore tends to neglect the broader aspects of contextual conditions in the wider school setting. Accordingly, this seems to be a challenge for educational research, and especially when trying to understand contextual conditions involved in processes of change and development.

\subsection{Suggestions for future research}

With these observations at hand, a number of suggestions for further research can be provided. Firstly, as mentioned above, there is a need to link different levels of the educational system to build further knowledge on digital competence in educational contexts. Future research should therefore elaborate on how a more comprehensive theorization and operationalization of pedagogical aspects of digital competence can be set out to develop links between policy, organizational infrastructures, strategic leadership and teachers and teaching practices (similar to From 2017). Secondly, compared to the comprehensive research on digital competence at the level of teachers, it seems that due to the review, it is reasonable to suggest that knowledge of organizational infrastructures and digital competent leadership needs to be further addressed. A third suggestion is for researchers to become involved in the development of new approaches to enhance digital competence in educational contexts. A fourth suggestion is that this type of review should be repeated regularly in order to build knowledge about the field over time and for the possibilities of results to be utilized and applied in both theory and practice.

\subsection{Concluding remarks and suggestions for practice}

Before ending this paper, some final suggestions will be made for practitioners and policymakers concerned with digital competence in educational contexts. Firstly, to make it possible for the development of digital competence, goals and visions should preferably be formulated in policy-related documents on multiple levels of the educational system, i.e., on an institutional, regional and national level. Policies can thereafter be transformed into realistic goals and concrete activities at the school level (similar to Dexter 2008; Petersen 2014). Secondly, schools organizations should develop institutional infrastructures that support and facilitate both their own and their staff's development of the competences needed for the work in digitalized schools (see Ottestad 2008; Vanderlinde and van Braak 2010). Thirdly, school leaders should help their staff to formulate goals and to recognize specific needs in order to reach these goals in the specific school setting (see Petersen 2014). Fourthly, digital competent leadership should not be excluded to single actors but rather to be thought of as a school-level characteristic including various professions, actors and competences (see Dexter 2008; 
Petersen 2014). Fifthly, single actors in schools also need to take responsibility for their development of digital competence and to reflect on how they enact digital competences in their own educational practices (see Wastiau et al. 2013; Tømte et al. 2015). Finally, teacher education needs to recognize the requirements that teacher-students will meet in digitalized schools (see Krumsvik 2012; Lund et al. 2014).

To conclude, this review of research literature has shown the potential regarding the development of digital competence as an activity that must be undertaken as an organizational task involving various professions, actors and competences (similar to Hauge and Norenes 2012; Petersen 2014). Such an activity, which concerns both research and practice, will have to involve multiple levels of the educational system with the shared object of educational change.

\subsection{Limitations in the review of research}

In this section some of the limitations of this review of research will be discussed. First of all, as for other reviews, finding articles and book chapters for inclusion depends on the logic behind the search. Despite the aim of a methodologically strict and inclusive search for this paper, alternative search terms might have resulted in additional articles and book chapters to be possibly included for review. One example is additional search terms related to digital competence within for example research institutes, World Bank, learning organizations, ministries, which were excluded in an attempt to delimit the review. These aspects would though be interesting for a follow up review. Moreover, in this review of research, database EBSCOhost (including both ERIC and Academic Search Elite) was used to find articles and book chapters for inclusion. However, another methodological option would had been to search for research in a number of pre-selected scientific peer-review journals. This might have resulted in a smaller sample of literature for inclusion but had probably made it easier to control aspects of validity, reliability and credibility during the searches and processes of inclusion (Stödberg 2012; Olofsson et al. 2015). To further ensure credibility, and to enable for inclusion of a larger number of articles, a continuation on this review could be to develop a web-based methodology for selecting literature. This could also include developing a feedback device to efficiently utilizing results of the literature review.

To sum up, the intention of this article has been to generate a source of knowledge and information on pedagogical aspects of digital competence in the educational context that contribute with knowledge useful to both researchers, educators and decision makers.

Open Access This article is distributed under the terms of the Creative Commons Attribution 4.0 International License (http://creativecommons.org/licenses/by/4.0/), which permits unrestricted use, distribution, and reproduction in any medium, provided you give appropriate credit to the original author(s) and the source, provide a link to the Creative Commons license, and indicate if changes were made.

\section{References}

Abdul Razzak, N. (2015). Challenges facing school leadership in promoting ICT integration in instruction in the public schools of Bahrain. Education and Information Technologies, 20(2), 303-318.

Afshari, M. A., Bakar, K. A., Luan, W. S., Abu Samah, B., \& Fooi, F. S. (2009). Technology and school leadership. Technology Pedagogy and Education, 18(2), 235-248. 
Ala-Mutka, K., Punie, Y., \& Redecker, C. (2008). Digital competence for lifelong learning [policy brief]. European Commission Joint Research Centre, Institute for Prospective Technological Studies. Retrieved from http://ftp.jrc.es/EURdoc/JRC48708.TN.pdf.

Balanskat, A., \& Gertsch, C. A. (2010). Digital skills working group. Review of national curricula and assessing digital competence for students and teachers: Findings from 7 countries. Brüssels: European Schoolnet.

Boote, D. N., \& Beile, P. (2005). Scholars before researchers: On the centrality of the dissertation literature review in research preparation. Educational Researcher, 34, 3-15.

Blau, I., \& Shamir-Inbal, T. (2017). Digital competences and long-term ICT integration in school culture: The perspective of elementary school leaders. Education and Information Technologies, 22(3), 769-787.

Bray, M., \& Thomas, R. (1995). Levels of comparison in educational studies: Different insights from different literatures and the value of multilevel analyses. Harvard Educational Review, 65(3), 472-490.

Dexter, S. (2008). Leadership for IT in schools. In J. Voogt \& G. Knezek (Eds.), International handbook of information technology in primary and secondary education (pp. 543-554). New York: Springer.

Engen, B. K., Giæver, T. H., \& Mifsud, L. (2015). Guidelines and regulations for teaching digital competence in schools and teacher education: A weak link? Nordic Journal of Digital Literacy, 10(2), 69-83.

Erstad, O., \& Quale, A. (2009). National policies and practices on ICT in education: Norway. In T. Plomp, R. E. Anderson, N. Law, \& A. Quale (Eds.), Cross-National Information and communication technology policies and practices in education (pp. 551-568). Charlotte: InformationAge Publishing.

Esteve-Mon, F. M., Cela-Ranilla, J. M., \& Gisbert-Cervera, M. (2016). Teach3D: Designing a 3D virtual environment for evaluating the digital competence of preservice teachers. Journal of Educational Computing Research, 54(6), 816-839.

Ferrari, A. (2012). Digital competence in practice: An analysis of frameworks. Sevilla: Joint Research Centre (JRC), European Commission.

From, J. (2017). Pedagogical digital competence- between values, knowledge and skills. Higher Education Studies, 7(2), 43-50.

Hatlevik, O. E., \& Arnseth, H. C. (2012). ICT, teaching and leadership: How do teachers experience the importance of ICT-supportive school leaders? Nordic Journal of Digital Literacy, 7(1), 55-69.

Hatlevik, O. E., \& Christophersen, K.-A. (2013). Digital competence at the beginning of upper secondary school: Identifying factors explaining digital inclusion. Computers \& Education, 63, 240-247.

Hatlevik, O. E. (2016). Examining the relationship between teachers' self-efficacy, their digital competence, strategies to evaluate information, and use of ICT at school. Scandinavian Journal of Educational Research. https://doi.org/10.1080/00313831.2016.1172501.

Hauge, T.-E., \& Norenes, S. O. (2012). VideoPaper as a bridging tool in teacher professional development. In J. O. Lindberg \& A. D. Olofsson (Eds.), Online learning communities and teacher professional development: Methods for improved education delivery (pp. 209-227). Hershey: Information Science Reference.

Hjerm, M., \& Lindgren, S. (2010). Introduktion till samhällsvetenskapliganalys [introduction to social scientific analysis]. Malmö: Gleerups Utbildning AB.

Howell, J. (2012). Teaching with ICT: Digital pedagogies for collaboration and creativity. Melbourne: Oxford University Press.

Ilomäki, L., Paavola, S., Lakkala, M., \& Kantosalo, A. (2016). Digital competence - An emergent boundary concept for policy and educational research. Education and Information Technologies, 21(3), 655-679.

Instefjord, E. (2014). Appropriation of digital competence in teacher education. Nordic Journal of Digital Literacy, 4(9), 313-329.

Instefjord, E., \& Munthe, E. (2016). Preparing pre-service teachers to integrate technology: An analysis of the emphasis on digital competence in teacher education curricula. European Journal of Teacher Education, 39(1), 77-93.

Kabakci, I. (2009). A proposal of framework for professional development of Turkish teachers with respect to information and communication technologies. Turkish Online Journal of Distance Education, 10(3), 204 216.

Kihoza, P. D., Zlotnikova, I., Bada, J. K., \& Kalegele, K. (2016). An assessment of teachers' abilities to support blended learning implementation in Tanzanian secondary schools. Contemporary Educational Technology, 7(1), 60-84.

Kivunja, C. (2013). Embedding digital pedagogy in pre-service higher education to better prepare teachers for the digital generation. International Journal of Higher Education, 2(4), 131-142.

Krumsvik, R. J. (2008). Situated learning and teachers' digital competence. Education and Information Technologies, 13(13), 279-290. 
Krumsvik, R. J. (2009). Situated learning in the network society and the digitised school. European Journal of Teacher Education, 32(2), 167-185.

Krumsvik, R. J. (2011). Digital competence in Norwegian teacher education and schools. Högre Utbildning, $1(1), 39-51$.

Krumsvik, R. J. (2012). Teacher educators' digital competence. Scandinavian Journal of Educational Research, 58(3), 269-280.

Krumsvik, R. J., Jones, L. Ø., Øfstegaard, M., \& Eikeland, O. J. (2016). Upper secondary school teachers' digital competence: Analysed by demographic, personal and professional characteristics. Nordic Journal of Digital Literacy, 11(3), 143-164.

Lund, A., Furberg, A., Bakken, J., \& Engelien, K. L. (2014). What does professional digital competence mean in teacher education? Nordic Journal of Digital Literacy, 9(4), 281-299.

Moore-Adams, B. L., Monty Jones, W., \& Cohen, J. (2016). Learning to teach online: A systematic review of the literature on K-12 teacher preparation for teaching online. Distance Education, 37(3), 333-348.

Newland, B., \& Handley, F. (2016). Developing the digital literacies of academic staff: An institutional approach. Research in Learning Technology, 24(1), 1-12.

Olofsson, A. D., Lindberg, J. O., Fransson, G., \& Hauge, T. E. (2015). Uptake and use of digital technologies in primary and secondary schools - A thematic review of research. Nordic Journal of Digital Literacy, 6(4), 103-121.

Ottestad, G. (2008). Schools as digital competent organizations: Developing organisational traits to strengthen the implementation of digital founded pedagogy. International Journal of Technology, Knowledge and Society, 4(4), 10.

Ottestad, G. (2010). Innovative pedagogical practice with ICT in three Nordic countries - Differences and similarities. Journal of Computer Assisted Learning, 26, 478-491.

Petersen, A. (2014). Teachers' perceptions of principals' ICT leadership. Contemporary Educational Technology, 5(4), 302-315.

Rantatalo, O. (2012). The miscellany of militaristic policing: A literature review. Journal of Policing, Intelligence and Counter Terrorism, 7(1), 51-65.

Sipilä, K. (2014). Educational use of information and communications technology: Teachers' perspective. Technology, Pedagogy and Education, 23(2), 225-241.

Søby, M. (2016). Digital competence - a password to a new interdisciplinary field. Nordic Journal of Digital Literacy, 10, 4-7.

Somekh, B. (2008). Factors affecting teachers' pedagogical adoption of ICT. In J. Voogt \& G. Knezek (Eds.), International handbook of information technology in primary and secondary education (pp. 449-460). London: Springer Science+Business Media.

Stuart, L. H., Mills, A. M., \& Remus, U. (2009). School leaders, ICT competence and championing innovations. Computers \& Education, 53(3), 733-741.

Stödberg, U. (2012). A research review of E-assessment. Assessment \& Evaluation in Higher Education, 37(5), 591-604.

Suri, H., \& Clarke, D. (2009). Advancements in research synthesis methods: From a methodologically inclusive perspective. Review of Educational Research, 79, 395-430.

Tondeur, J., van Braak, J., Sang, G., Voogt, J., Fisser, P., \& Ottenbreit-Leftwich, A. (2012). Preparing preservice teachers to integrate technology in education: A synthesis of qualitative evidence. Computers \& Education, 59(1), 134-144.

Tømte, C., Enochsson, A., Buskqvist, U., \& Kårstein, A. (2015). Educating online student teachers to master professional digital competence: The TPACK-framework goes online. Computers \& Education, 84, 26-35.

Røkenes, F. M., \& Krumsvik, R. J. (2016). Prepared to teach ESL with ICT? a study of digital competence in Norwegian teacher education. Computers \& Education, 97, 1-20.

van Niekerk, M., \& Blignaut, S. (2014). A framework for information and communication technology integration in schools through teacher professional development. Africa Education Review, 11(2), 236253.

Vanderlinde, R., \& van Braak, J. (2010). The e-capacity of primary schools: Development of a conceptual model and scale construction from a school improvement perspective. Computers \& Education, 55, 541553.

Vanderlinde, R., \& van Braak, J. (2011). A new ICT curriculum for primary education in Flanders: Defining and predicting teachers' perceptions of innovation attributes. Journal of Educational Technology \& Society, 14(2), 124-135. 
Wanjala, M. S. (2016). Information communication technology pedagogical integration in mathematics instruction among teachers in secondary schools in Kenya. Journal of Education and Practice, 7(2), 66-73.

Wastiau, P., Blamire, R., Kearney, C., Quittre, V., Van de Gaer, E., \& Monseur, C. (2013). The use of ICT in education: A survey of schools in Europe. European Journal of Education, 48(1), 11-27.

Wei, L. M., Piaw, C. Y., Kannan, S., \& Moulod, S. A. (2016). Relationship between teacher ICT competency and teacher acceptance and use of school management system (SMS). Malaysian Online Journal of Educational Technology, 4(4), 36-52. 